\title{
ESTADO, CIDADANIA E OUVIDORIAS PÚBLICAS NO BRASIL
}

\author{
Eric Ferdinando Kanai Passone ${ }^{1}$ \\ José Roberto Rus Perez ${ }^{2}$ \\ Adriana Eugênia Alvim Barreiro ${ }^{3}$
}

\begin{abstract}
Resumo
O presente artigo aborda a institucionalização de Ouvidorias Públicas no processo de democratização do Estado e da sociedade brasileira. A relevância de se abordar as Ouvidorias Públicas no cenário brasileiro, após sua emergência e expansão nas últimas décadas, relaciona-se à sua específica função mediadora entre Estado e sociedade. Indaga-se sobre o papel das Ouvidorias, ora vistas como um mecanismo emergente do neoliberalismo, ora vistas como uma instância de reconhecimento e efetivação dos direitos de cidadania, ampliação de espaços públicos para inúmeras formas de participação social e accountability do Estado junto à sociedade civil. Essa condição mediadora das Ouvidorias seria somente um mecanismo para reduzir e amortecer os conflitos entre a sociedade e o Estado ou prestar-se-ia à defesa e garantia de direitos de cidadania? Destacam-se considerações sobre a consolidação das Ouvidorias com relação à gestão de políticas públicas.
\end{abstract}

Palavras-Chave: Ouvidoria Pública. Gestão Pública. Políticas Públicas e Cidadania.

1 Doutor em Educação pela Universidade Estadual de Campinas - Unicamp. Pesquisador Colaborador no Núcleo de Estudos de Pesquisas (NEPP) na Universidade Estadual de Campinas - Unicamp. São Paulo, Brasil.

2 Livre Docente na Universidade Estadual de Campinas - Unicamp. Faculdade de Educação. Departamento de Políticas, Administração e Sistemas Educacionais. São Paulo, Brasil.

3 Ouvidora-Geral, no período de 2001 a 2107, na Universidade Estadual de Campinas - Unicamp. Membro do Grupo de Estudos e Pesquisas em Educação Moral - GEPEM, na Universidade Estadual de Campinas - Unicamp. Faculdade de Educação. São Paulo, Brasil. 


\begin{abstract}
The present article approaches the Public Ombudsman's Offices institutionalization in Brazilian state and society democratization process. The relevance of this approach to the Public Ombudsman's Offices in the Brazilian context, which it had emerged and expanded in the last few decades, is its specific function as a mediator between state and society. We attempt to exam its function, which are sometimes seen as neoliberalism mechanism emerging and also seen as an instance of awareness and the exercise of civil rights, expansion the public space by innumerable way of social participation and state accountability with the civil society. Does this Ombudsman's Office mediator condition just reduce and weaken conflicts between society and state? Or does it serve as civil rights protection mechanism? This research emphasizes on consideration about Ombudsman's Office consolidation related to the public politics management.
\end{abstract}

Keywords: Public Ombudsman's Office. Public Management. Public Policy and Citizenship. 


\section{INTRODUÇÃO}

Este texto aborda a relação entre a cultura política brasileira e a institucionalização da participação social nos mecanismos de controle e acompanhamento das políticas públicas, tendo como foco a emergência dos serviços de Ouvidorias Públicas. Este trabalho trata especificamente das Ouvidorias Públicas, compreendendo-as como aquelas vinculadas aos setores estatais (poderes executivos, legislativos e judiciários nos níveis federal, estadual e municipal), resguardando as diferenças existentes entre as Ouvidorias Públicas e as Ouvidorias Privadas ${ }^{4}$.

Neste percurso, partir-se-á da noção de indissolubilidade entre cultura e política. A primeira é compreendida enquanto produção e circulação de significados e representações constitutivas das práticas humanas; a segunda, por sua vez, se configura como um campo marcado por relações de poder e força, conflitos e disputas de interesses, caracterizada por sua pluralidade e, consequentemente, fragmentada em suas demandas, sendo, muitas vezes, carente de mediadores dos conflitos inerentes às sociedades democráticas e pluralistas. Este artigo visa contribuir tanto para o debate quanto para a consolidação das Ouvidorias no cenário da Administração Pública brasileira, buscando o aprimoramento das instituições e organizações, cuja finalidade é garantir os direitos dos cidadãos e prestar serviços à sociedade por meio da problematização da cultura política brasileira enquanto construção de referências ao exercício profissional do ouvidor (RUS PEREZ et al., 2011).

Propõe tratar da indissolubilidade entre cultura e política, o que implica o reconhecimento de que tal discussão engloba o caráter heterogêneo e fragmentado do Estado e da Sociedade Civil, seus diferentes projetos políticos e o padrão de intervenção estatal junto à sociedade no que concerne ao reconhecimento dos direitos constitutivos de cidadania.

Apresentar-se-ão as principais características da cultura política brasileira, bem como serão explorados temas contemporâneos que transpassam o debate sobre a democratização societária e institucional, como os diferentes projetos que compõem a sociedade civil, os espaços públicos e a própria noção de democracia e cidadania. Tal dimensão, por exemplo, torna-se fundamental para a compreensão dos fatores políticos e culturais que envolvem a participação social e as relações existentes no âmbito do atendimento das Ouvidorias, uma vez que tais órgãos se tornaram importantes mediadores entre o cidadão e a gestão pública 5 .

$\mathrm{Na}$ atualidade, os campos de análises das ciências sociais se focam em estudos que articulam diferentes mecanismos de participação e controle social com o movimento político de democratização do país. Esses estudos têm assinalado mudanças de escopo nas análises, destacando-se duas dimensões principais. A primeira delas é a tendência à superação da dicotomia sociedade/ Estado, interpretada como antagonismo na tradicional filosofia política, por uma ênfase baseada

4 Como este artigo não abordará de forma sistemática as diferenças entre as Ouvidorias Públicas e Privadas, recomendamos para tanto consultar os trabalhos: Ouvidorias Públicas e Privadas: Farinha do mesmo saco? (LYRA, 2009); A Ouvidoria como instrumento para a efetividade da ação pública e promoção da cidadania (COSTA, 2010); e Regime jurídico das Ouvidorias Públicas: elementos para uma tipologia (GOMES, 2005).

5 Explicitamos os nossos agradecimentos aos Ouvidores e participantes do Curso de Ouvidoria Pública e Privada no Brasil, realizado pelo Instituto de Economia da Universidade Estadual de Campinas em 2008 e 2010, pelas contribuições, debates e questões que ajudaram em nossas reflexões neste trabalho. 
em termos de sinergia, complementaridade e cogestão, envolvendo o binômio Estado-sociedade. A segunda é a "ênfase na compreensão empírica de processos em curso, notadamente os alcances, entraves e limitações das novas formas de interação entre sociedade civil e o Estado" (LAVALLE, 2003, p. 109). Com base nesse contexto, os serviços de Ouvidorias e agências de controle interno inserem-se no amplo processo de democratização que abarca desde a prestação de contas, o controle da qualidade dos serviços públicos, a transparência dos diversos níveis e setores administrativos de governo, até o planejamento e gestão das políticas públicas.

\section{ESTADO, DIREITOS E CIDADANIA}

No Brasil, o processo de construção democrática envolve contradições e ambiguidades históricas, tanto na perspectiva cultural e política, quanto na perspectiva institucional. Estas, uma vez reveladas e refletidas pela trajetória política brasileira, nos auxiliam na compreensão do papel e da possibilidade mediadora das Ouvidorias. Isso implica fazer um retorno aos primórdios do desenvolvimento político do Estado brasileiro, sua relação com a oferta de políticas sociais e o desenvolvimento dos direitos de cidadania.

Historicamente, tal processo caracterizou-se pela indistinção entre o mundo público e o privado, pela cultura política do patrimonialismo, do clientelismo e pelo excesso de poder executivo em detrimento dos poderes legislativo e do judiciário, gerando uma relação Estado-sociedade que sempre supervalorizou o poder executivo e, por conseguinte, suas formas tradicionais de regulação social da organização societária. José Murilo de CARVALHO (2004) denominou de "estadania" tal relação unilateral e direta entre o Estado e o indivíduo, sendo o primeiro representado como aquele ente "todo poderoso", que ora "reprime e cobra impostos", ora se apresenta como um "distribuidor paternal de benefícios, empregos e favores". Pode-se, também, citar FAORO (2001), que nos revelou de forma contundente as raízes dos interesses privados na formação do poder político brasileiro. Essa característica remete à fatídica herança do colonialismo e do patrimonialismo imperial, marcados pelo domínio do poder político sob a predominância do fator econômico e dos interesses privados. Os "donos do poder" ou o "patronato político brasileiro" representavam as elites regionais dominantes, cujo poder econômico se apropriava dos sistemas políticos. O patrimonialismo era garantido culturalmente pela "cordialidade" das relações de clientelismo e pelo violento sistema do "voto de cabresto", característico nas disputas eleitorais desde a República Velha. Como herança histórica, o patrimonialismo se expressa, na cultura política brasileira, como a influência do poder econômico na determinação eleitoral e, principalmente, na indissociabilidade entre o mundo público e o mundo privado.

Em outra dimensão, na perspectiva institucional, trata-se de reconhecer o desenvolvimento do arcabouço sociojurídico que regula o processo político de organização da sociedade. Nesse caso, os estudos de políticas públicas constatam que, entre o período de 1930 e 1980, ocorreu a introdução, a expansão e a consolidação institucional-jurídica dos mecanismos de garantia social e subvenção de renda, como a previdência social e a assistência; a construção de uma rede de ensino básico e científico; a política de atenção à saúde e a política habitacional. 
O desenvolvimento e a consolidação do sistema brasileiro de proteção social foram marcados por um tipo específico de Estado de Bem-Estar Social, cujo funcionamento se caracterizou pelo tipo "meritocrático-particularista" e/ou "modelo conservador" (DRAIBE, 1995, p. 201), segundo a classificação-tipologia de TITMUSS e ESPING-ANDERSON, respectivamente, diferente tanto de um modelo residual ou liberal quanto de um padrão institucional-redistributivista ou social-democrata. Segundo MEDEIROS (2001), "tipos meritocráticos-particularistas tendem, no limite, a reforçar as desigualdades preexistentes", servindo de mecanismos de "estratificação social", uma vez que as políticas sociais não são concebidas para todos, inscrevendo-se, assim, como modelo particularista de Estado de Bem-Estar ou Estado-Providência.

Também é relevante mencionar que os três maiores momentos de transformações institucionais e de produção de legislação social estiveram associados às três profundas alterações envolvendo o Estado brasileiro no século XX, a saber, o Estado Novo, caracterizado pelo autoritarismo populista de Getúlio Vargas (1930-1945); a Ditadura Militar (1964-1985), e o período de redemocratização, a partir de 1985 (CARVALHO, 2004; NEPP, 1991). Além disso, o desenvolvimento do arcabouço de proteção social manteve estreitas relações com os períodos autoritários (Estado Novo e o Regime Militar), limitando-se, assim, à regulação social e à concessão de direitos somente para certos estratos sociais. A concessão de direitos ocorreu por meio da incorporação gradativa de segmentos sociais ao sistema, em detrimento do reconhecimento e garantia dos direitos civis, políticos e sociais à sociedade em geral.

Assim, constituído o dispositivo político de regulação social, foi denominado pelo conceito de "cidadania regulada", proposto por SANTOS (1989), sendo a mesma entendida como "o conceito de cidadania cujas raízes encontram-se não em um código de valores políticos, mas em um sistema de estratificação ocupacional na qual os direitos do cidadão restringem-se aos direitos do lugar que ocupa no processo produtivo, tal como reconhecido por lei..." (SANTOS, 1989, p. 68). Enfim, a cidadania regulada representou o privilégio de alguns grupos de trabalhadores em detrimento do reconhecimento de direitos da população como um todo, característica marcante da cultura política no Brasil.

De modo diverso, nos países centrais da Europa, o desenvolvimento progressivo de direitos (civis, políticos e sociais) foi de ordem política, mobilizando em larga escala a participação civil, esta alicerçada pelo reconhecimento das liberdades civis e individuais. $\mathrm{O}$ trabalho de T. H. MARSHALL (1967), Cidadania e Classe Social, que expressa tal pensamento, considera a emergência das políticas igualitárias do século XX em função do desdobramento dos direitos civis no século XVIII; dos direitos políticos no século XIX e dos sociais no século XX. Para MARSHALL, a cidadania está composta por estas três dimensões ou direitos: os civis (relacionados às liberdades individuais, como o direito de ir e vir, além das conquistas no campo das relações de trabalho); os políticos (relacionados ao direito de organização política e de participação do povo no exercício do poder político de uma sociedade), e, finalmente, os sociais (associados à participação individual e coletiva na riqueza que é produzida pela sociedade). Nas sociedades modernas, tais conquistas evoluíram ao longo da história de acordo com os níveis de mobilização e organização social, determinando as diferenças no desenvolvimento dos direitos que compõem a noção de cidadania entre distintos países. 
No Brasil, pode-se dizer que o processo de constituição dos direitos da cidadania ocorreu de forma "invertida", ou seja, os direitos sociais foram anteriores à conquista dos direitos civis e políticos, implicando a formação de um tipo especial de cidadania, na qual a relação entre indivíduo e o Estado teve como marca a negociação direta entre ambos, sem passar por mecanismos de representação política e democrática. Para CARVALHO (2004), "primeiro vieram os direitos sociais, implantados em período de supressão dos direitos políticos e de redução dos direitos civis", durante o populismo autoritário da era Vargas. Em suas palavras, "a maior expansão do direito do voto deu-se em outro período ditatorial, em que os órgãos de representação política foram transformados em peça decorativa do regime" (CARVALHO, 2004, p. 219). Esse entendimento implica, necessariamente, reconhecermos a base frágil da cultura política brasileira, com relação aos direitos constitutivos de cidadania, principalmente em questões que suscitam o reconhecimento do outro como portador de direitos. A mesma inversão da sequência de direitos reforçou o poder e o papel predominante do Estado, na cultura política brasileira, como ente que concede ou nega a condição de cidadão aos indivíduos.

Paralelamente, os momentos históricos de totalitarismo e a elaboração crítica de tais sistemas permitiram a explicitação de um programa de ação para combatê-los: "se há algo importante a fazer em termos de consolidação democrática, é reforçar a organização da sociedade para dar embasamento social ao político, isto é, para democratizar o poder" (CARVALHO, 2004, p. 227). Essa visão destina-se ao combate do autoritarismo social antidemocrático, por um lado, e à promoção de uma cultura política destinada à socialização do poder político do Estado, por outro. Segundo CARVALHO, "a organização da sociedade não precisa e não deve ser feita contra o Estado em si. Ela deve ser feita contra o Estado clientelista, corporativo, colonizado" por interesses particulares (Idem, p. 227).

A organização social democrática baseia-se na interação da sociedade civil com o Estado, implicando o reconhecimento dos valores democráticos nas práticas cotidianas; assim, os critérios democráticos não devem permanecer confinados à esfera institucional; ao contrário, eles devem "penetrar no tecido das relações sociais e na cultura política gestadas nesse nível" (COSTA, 1999), por meio do reconhecimento dos direitos aos cidadãos. O binômio Estado-sociedade precisa garantir condições de reconhecimento aos indivíduos como portadores de direitos, proporcionando-lhes a incorporação de valores ético-políticos, e oferecendo-lhes elementos de identificação com a organização democrática da sociedade, com a res pública e o bem comum.

O desenvolvimento dos direitos de cidadania e a institucionalização da participação política e social, conquistas imprescindíveis à sociedade brasileira, consolidaram-se na Constituição de 1988 e têm possibilitado, desde então, a criação e fortalecimento de mecanismos de interlocução e cogestão entre o Estado e Sociedade em todos os níveis e setores, tais como os conselhos setoriais de políticas públicas, os fundos públicos, os orçamentos participativos, os serviços de Ouvidoria, a defensoria pública etc. (GEDC, 1999; DAGNINO et al., 2006).

$\mathrm{Na}$ Constituição promulgada em 1988 estão previstos os conselhos gestores de políticas públicas, os quais possuem caráter compulsório e papel fundamental no processo de descentralização e operacionalização das políticas públicas, nos diversos níveis estatais (federal, estadual e municipal). Os orçamentos participativos e as Ouvidorias Públicas, embora não sejam previstos de forma específica no texto constitucional, possuem legislações particulares de acordo com o nível de sua 
implementação. Tal fato explica a existência de diversos mecanismos institucionais relacionados à implementação desses órgãos, ou mesmo a inexistência dos orçamentos participativos e Ouvidorias em municípios, que muitas vezes dependem das capacidades técnico-econômicas e/ou vontade política dos governos locais. Pode-se citar como exemplo a implantação das Ouvidorias Públicas nos órgãos vinculados ao poder executivo estadual de São Paulo, que possui sua institucionalização nos termos da Lei 10.294, de 20 de abril de 1999, cuja normatização refere-se à proteção e defesa do usuário do serviço público do Estado de São Paulo.

A consolidação de tais mecanismos depende de promoção e capacitação das organizações que compõem o binômio Estado-sociedade, no sentido de gerir coletivamente a construção de regras e parâmetros públicos, assim como da proposição de uma rede continuada de procedimentos destinados ao acompanhamento das políticas públicas que acentuem a reinvenção de um Estado ético-político para a sociedade civil (NOGUEIRA, 2004), considerando-se a indissociabilidade entre os vínculos do Estado e da sociedade civil nas sociedades democráticas e capitalistas. Tal definição alinha-se com a noção de Estado ampliado, em que, segundo $\operatorname{GRAMSCI}(2000$, p. 28), o "Estado deve ser concebido como 'Educador' na medida em que tende precisamente a criar um novo tipo ou nível de organização", utilizando para isso o direito (ao lado da educação), como instrumento, para "criar e manter um certo tipo de civilização e de cidadão". GRAMSCI (2000) desenvolveu uma teoria sobre o "Estado integral", o que se convencionou chamar de "teoria ampliada do Estado". O Estado não compreende somente o aparelho jurídico coercitivo, mas também a sociedade civil, enquanto campo do embate político por excelência, espaço da produção de consenso e da formulação de projetos a se tornarem hegemônicos. Nesse sentido, a hegemonia é compreendida, basicamente, como um processo gradual e renovado de implementação de um projeto de transformação social, capaz de articular diferentes interesses. Como referência, citamos NOGUEIRA (2003), para quem a hegemonia pode ser compreendida como a "capacidade que um grupo tem de dirigir eticamente os demais grupos e estabelecer um novo campo de liderança". Assim, a sociedade civil também é entendida como detentora de funções estatais, na mesma medida em que se põe como "hegemonia política e cultural de um grupo social sobre toda sociedade, como conteúdo ético do Estado". Nesse caso, o conceito de sociedade civil é um instrumento pelo qual se pode compreender e transformar a realidade: “... sociedade civil é um conceito, completo e sofisticado, com o qual se pode entender a realidade contemporânea. Mas é também um projeto político, abrangente e igualmente sofisticado, com o qual se pode tentar transformar a realidade" (NOGUEIRA, 2003, p. 186).

As diversas formas de organização da sociedade civil e a criação de espaços públicos de participação política e social viabilizaram, pela primeira vez na história brasileira, a valorização e/ ou reconhecimento do "outro" como sujeito e portador de direitos, contribuindo para a constituição de espaços públicos para aprendizagem de uma cultura de direitos (GECD, 1999). Tais espaços originaram-se tanto nos anos de luta contra os períodos políticos autoritários quanto na organização societária por direitos civis, políticos e sociais. Sabe-se que a construção democrática, no país, tem disposto três projetos políticos diferentes, a saber, os projetos autoritário, (neo)liberal e democrático-participativo. Os mesmos colocam suas respectivas tendências políticas em disputa na sociedade civil, na burocracia estatal e nesses espaços públicos de participação, visando tanto o consentimento social como a conquista do poder (DAGNINO, 2004; NOGUEIRA, 2004). Logo, a luta 
pela democratização concretiza-se por meio desses antagonismos, que retratam os conflitos entre os distintos projetos de hegemonia subjacentes à sociedade civil e política brasileira, transpassando grupos, organizações e instituições da contemporaneidade.

\section{DEMOCRATIZAÇÃO, POLÍTICAS PÚBLICAS E CONTROLE SOCIAL}

O processo de democratização não é considerado, no presente texto, como um mero momento de transição do sistema político, mas, antes, como um processo permanente de concretização da soberania popular, conjuntamente com a constituição de instituições democráticas (eleições livres, sufrágio universal, parlamento ativo, liberdade de imprensa etc.), que se desdobram de modo contraditório no desenvolvimento histórico da sociedade. Segundo COSTA (1999), "a existência da democracia implica a incorporação dos valores democráticos nas práticas cotidianas, emergentes do tecido das relações sociais e da cultura política gerada neste nível". Portanto, a construção democrática passa pelo reconhecimento dos direitos de cidadania como vetor axiológico das relações sociais, em que cada sujeito passa a ser reconhecido e identificado, em suas interações sociais, como portador de direitos e deveres inalienáveis ao cidadão.

No caso brasileiro, no final do século $X X$, assistiu-se à crescente organização da sociedade contra a ditadura e em favor da liberdade e da democracia, que culminou na conquista dos direitos de expressão individual e coletiva, de organização popular e partidária, de greve, de liberdade de opinião etc. O período de redemocratização do Estado brasileiro caracterizou-se por sua reforma administrativa, envolvendo a descentralização e a municipalização de políticas públicas e, também, a institucionalização do controle social, com o desenvolvimento de conselhos e espaços públicos de interlocução e cogestão política.

No plano político-econômico, o dilema que se estabeleceu foi o de conciliar crescimento econômico com o cenário de escassez de recursos públicos, por um lado, e demandas por uma democracia social, por outro. Em decorrência, a estratégia de constituição de um sistema de proteção social se baseou nos modelos tradicionais de programas destinados à transferência monetária com vistas às famílias em vulnerabilidade social, ou seja, por intermédio de políticas sociais compensatórias e complementares, objetivando-se aumento de acesso à alimentação, saúde e educação básica, enquanto fatores de grande potencial para a redução das desigualdades.

Houve, também, uma demanda expressiva de políticas sociais em favor da justiça e equidade social e do combate à pobreza. No entanto, tais políticas foram marcadas pela focalização e seletividade de sua cobertura, com o avanço do universalismo em algumas áreas (como saúde e educação); pela luta por redução do estatismo, com preservação do caráter público e gratuito dos serviços, mediante aprofundamento da articulação com organizações sociais e com o setor privado, e pela maior aceitação e apoio, no meio político, aos programas de transferência monetária direta, como os de renda mínima e combate à pobreza (DRAIBE, 2005). Concomitantemente, ocorreram a institucionalização da participação social e a reforma estatal, com a extensão de organizações da sociedade civil atuando na garantia de direitos públicos e subjetivos. Assim, a partir da regulamentação da Constituição da República Federativa do Brasil, em outubro de 1988, constituíram-se as 
principais legislações com base nos direitos sociais: o Estatuto da Criança e do Adolescente (Lei Federal n 8.069/90); a Lei Orgânica da Saúde - LOS (Lei Federal n 8.080/90); o Conselho Nacional dos Direitos da Criança e do Adolescente - CONANDA (Lei Federal n 8.242/91); a Lei Orgânica da Assistência Social - LOAS (Lei Federal n 8.742/93); a Lei de Diretrizes e Bases da Educação Nacional - LDBEN (Lei Federal n 9.394/96); a Lei Orgânica de Segurança Alimentar - LOSAN (Lei Federal $\left.n^{0} 11.346 / 06\right)$, além da recente integração dos serviços sociais, por meio do Sistema Único de Assistência Social - SUAS. Este alicerce legal estabeleceu as políticas sociais básicas destinadas às necessidades primordiais dos cidadãos, como saúde, educação, cultura, alimentação, esporte, lazer, profissionalização, considerando o acesso aos direitos sociais uma dimensão da cidadania (BRASIL, 1988).

Destaca-se que o sistema político gerado pela Constituição foi caracterizado como um modelo híbrido que incorporou em sua organização amplas formas de participação social no plano do processo decisório federal, assim como nos planos estaduais e municipais. Tal institucionalidade representou avanços em termos de direitos políticos, garantindo a representação direta e indireta em suas estruturas constituintes. Nesse sentido, AVRITZER (2006) enfatiza que a Constituição combinou, no seu escopo democrático, tanto formas de representação como formas de participação. $O$ artigo 14, incisos I, II e III, expressa essa combinação quando garante que "[a] soberania popular será exercida pelo sufrágio universal e pelo voto direto e secreto, com valor igual para todos, e nos termos da lei, mediante: plebiscito, referendo e iniciativa popular". Assim, o Brasil se inseriu em um grupo seleto de "países que não têm na representação o monopólio das formas de expressão política institucionalizadas. [...] Uma segunda forma de participação, centrada no nível local, proliferou como decorrência da participação exigida por alguns capítulos de políticas sociais..." (AVRITZER, p. 35). Consequentemente, constituíram-se e consolidaram-se os mecanismos de participação, controle, interlocução e cogestão entre Estado e sociedade civil, tais como os conselhos gestores de políticas públicas (saúde, educação, assistência, criança e adolescente, idosos etc.), os conselhos de direitos etc. (AVRITZER, 2006; GEDC, 1999).

Nesse contexto, as Ouvidorias Públicas surgiram como um canal de comunicação, informação, participação e aprendizagem de direitos, que se propõe à mediação entre Estado e sociedade. De uma forma geral, os fundamentos legais dessa instituição baseiam-se no artigo 37 da Constituição, o qual dispõe sobre os princípios inerentes à Administração Pública, como a legalidade, a impessoalidade, a moralidade, a publicidade e a eficiência (COSTA, 2010; LYRA, 2009; VISMONA, 2005). A redação da Emenda Constitucional $n^{\circ} 19$, de 1998, para o artigo 37, definiu no $\S 1^{\circ}$ que "a publicidade dos atos, programas, obras, serviços e campanhas dos órgãos públicos deverá ter caráter educativo, informativo ou de orientação social..." e, no $\S 3^{\circ}$, dispõe e garante "a participação do cidadão na Administração Pública direta e indireta", regulando especialmente:

I - as reclamações relativas à prestação dos serviços públicos em geral, asseguradas a manutenção de serviços de atendimento ao usuário e a avaliação periódica, externa e interna, da qualidade dos serviços;

II - 0 acesso dos usuários a registros administrativos e a informações sobre atos de governo, observado o disposto no art. $5^{\circ}, \mathrm{X}$ e XXXIII;

III - a disciplina da representação contra o exercício negligente ou abusivo de cargo, emprego ou função na Administração Pública. 
Os mesmos princípios visam o controle das atividades administrativas dos entes que integram a federação brasileira (União, Estados, Distrito Federal e Municípios) e, como preceitos constitucionais, subsidiaram, nas últimas décadas, a elaboração e implementação de Ouvidorias Públicas no país, respeitando as diversidades culturais e regionais, face às características do sistema federativo. Assim, as Ouvidorias evoluíram de acordo com a organização política de cada esfera de unidade administrativa. Em Curitiba, por exemplo, cuja Ouvidoria foi uma das pioneiras no país, essa foi prevista na Lei Orgânica Municipal de 1990, com atributos recomendando à autoridade administrativa as providências cabíveis, nos casos de morosidade, ilegalidade, abuso de poder, omissão, negligência, erro ou violação dos princípios constitucionais. Também em consonância com o artigo 37 da Constituição, destaca-se a Lei de Proteção de Defesa do Usuário do Serviço Público do Estado de São Paulo, n 10.294, de 1999, que instituiu o sistema de Ouvidorias do Estado. Tal sistema foi regulamento pelo Decreto $n^{\circ} 44.074$, de 1999, o qual estabeleceu as competências das Ouvidorias de serviços públicos do Estado. De acordo com o decreto, compete aos serviços de Ouvidoria "exercer a função de representante do cidadão junto à instituição em que atua" (Art. 1). Estabeleceu, ainda, nos Artigos $3^{\circ}$ e $4^{\circ}$, que o "Ouvidor exercerá suas funções com independência e autonomia, sem qualquer ingerência político-partidária, visando garantir os direitos do cidadão usuário do serviço público".

Configurando importante marco legal na regulação das atividades das Ouvidorias Públicas do Estado de São Paulo, em abril de 2014 foi promulgado o Decreto $n^{\circ} 60.399$, que, entre outros, ratifica as competências e garantias para o bom funcionamento, além de organizar os procedimentos, estabelecer prazos e apresentar as orientações concernentes aos relatórios. Em março de 2015 estabeleceu-se o Decreto n 61.175 conferindo a denominação da Ouvidoria-Geral, no Estado de São Paulo, e estabelecendo sua organização. Estes instrumentos legais corroboram para a gradual consolidação das Ouvidorias Públicas paulistas, sua legitimação como valoroso espaço democrático de participação cidadã.

Pode-se afirmar que a função de Ouvidor surgiu com a finalidade de controle interno e externo à Administração Pública, com princípios de independência e autonomia, e a incumbência de atender direitos básicos do cidadão, como o direito à informação, à qualidade nos serviços públicos prestados pela administração direta e indireta e ao controle social das instituições do Estado. Assim, a Ouvidoria pode ser compreendida na intersecção entre o controle interno e externo. Por um lado, como controle interno, a Ouvidoria pode ser um mecanismo de gestão preventiva a riscos visando à alta administração, no processo de gerenciamento e busca de resultados efetivos. Por outro, como instrumento de controle social, "pode aumentar o valor de confiabilidade da organização perante a sociedade e ser mais um meio de participação direta da sociedade na gestão, fortalecendo a democracia" (ANTUNES, 2010).

A transparência da Administração Pública é pressuposto de governos, sendo que o papel do Ouvidor vem sendo considerado como o de "representante dos interesses legítimos dos cidadãos", que acolhe demandas, regula as relações entre os indivíduos e o Estado, atua em defesa dos direitos do cidadão, no aperfeiçoamento da Administração Pública e do próprio processo democrático. Assim, uma Ouvidoria bem estruturada, respaldada pela alta administração, com independência para apresentar suas sugestões e autonomia em verificar as causas das reclamações, é um ótimo 
suporte para auxiliar na melhoria da qualidade de serviços e produtos (VISMONA, 2015). Pode-se, então, indagar sobre a publicização e legitimidade da Ouvidoria perante a sociedade brasileira: quantos cidadãos conhecem as funções das Ouvidorias e sabem utilizá-las? Será que as Ouvidorias respondem aos anseios dos cidadãos, ou carecem de legitimidade perante a sociedade? E, no interior das Administrações Públicas, sua autonomia, independência, funções e demandas são reconhecidas, respeitadas e respondidas por seus pares?

Os mecanismos acima descritos representaram a institucionalização dos espaços de participação e controle social, gerando novos desafios à organização democrática da sociedade, em especial no que diz respeito à governança política, tendo como agravantes disfuncionais os contextos de forte instabilidade econômica, profunda fragmentação social e heterogeneidade de projetos estatais e sociais, que tencionaram de diferentes modos a luta pela hegemonia política sobre o padrão de intervenção estatal. Uma das principais questões envolvendo a reforma estatal, a gestão e a oferta de políticas públicas no final do século XX ateve-se às disputas entre grupos, com diferentes interesses sobre o orçamento do gasto social, bem como sobre os modelos de financiamento público-privado e o padrão estatal de intervenção.

O debate sobre o financiamento e agenciamento econômico de tais políticas foi delimitado por duas posições distintas, que marcaram as lutas e os conflitos no campo das ideias e dos interesses, em torno das políticas públicas e do papel do Estado. Essas posições diferentes estavam associadas às perspectivas ideológicas antagônicas que circulam no cenário macroeconômico e político desde o início do século XX: por um lado, a posição progressista representada pela social-democracia, a qual defende a primazia da equidade social entre os indivíduos e a responsabilidade do Estado sobre as questões econômicas e sociais, e, por outro, a posição mais conservadora representada pelos ditames (neo)liberais, que não admite a interferência do Estado no campo econômico e sobre as liberdades individuais, para a emancipação individual e regulação social-política-econômica (JOHN, 1999).

Nas últimas décadas, constatou-se que as diferenças de ideias e interesses influenciaram a produção e oferta de políticas públicas, seja no sentido de pressionar por um Estado mínimo, ou, de modo oposto, por reivindicar um Estado intervencionista. Na atualidade, o ideário neoliberal passou da ênfase em recomendações do Estado Mínimo, "visando superar a crise econômica, a partir da negação dos princípios social-democratas de regulação econômica", para um segundo momento, marcado pela ênfase em políticas de crescimento econômico "apoiado na elevação da competitividade sistêmica e no reforço a mecanismos de modernização e flexibilização das estruturas e investimentos sociais, condizentes com as novas tecnologias" de gestão de políticas públicas (DRAIBE, 1994, p. 91). Dessa forma, houve o reconhecimento de que a pobreza impõe entraves à modernização das economias e à consolidação dos regimes democráticos, induzindo, assim, à representação propositiva de uma nova institucionalidade regulatória e participativa, por intermédio da qual vêm se redesenhando as políticas sociais, como a criação de um mercado de serviços, através do provimento de serviços sociais básicos. O processo de institucionalização dos meios de participação social nas decisões de políticas públicas representou a proliferação de estratégias de monitoramento e acompanhamento das políticas estatais, marcando uma nova fase de gerenciamento das ações estatais e das políticas públicas. O controle social da sociedade sobre o Estado 
inclui "mecanismos de acompanhamento e monitoramento da sua atuação por parte da sociedade, de modo a garantir o seu caráter público, prática que tem sido denominada 'prestação de contas', ou accountability" (DAGNINO et al., 2006, p. 50).

Identifica-se na América Latina, de acordo com os estudiosos, a emergência de três tipos ou modelos de controle social. O primeiro diz respeito às iniciativas de organizações e grupos da sociedade civil que "assumiram como tarefa a vigilância de algum órgão do Estado ou algum processo político", citando, por exemplo, ações de organizações não governamentais, tais como a experiência brasileira da organização Transparência Brasil, ou o Observatório da Cidadania. O segundo modelo refere-se às novas instituições do Estado, destinadas a "garantir o direito à informação ou ajudar a cidadania a vigiar o exercício do governo". Por último, o terceiro modelo retrata as tendências globais de desenvolvimento institucional do setor público, baseado no processo de criação de agências autônomas de controle interno dentro próprio Estado, como as controladorias ou corregedorias.

A heterogeneidade do Estado a as distintas vontades políticas dos encarregados dessas agências são algumas variáveis a levar em conta para explicar diferenças de atuação. $O$ mesmo se passa no Brasil, onde, por exemplo, a criação generalizada de Ouvidorias nos diversos níveis de governo e agências estatais tem impactos variados (DAGNINO et al., 2006, p. 51).

Desse modo, pode-se indagar sobre o papel das Ouvidorias, ora vistas como um mecanismo institucional emergente do neoliberalismo, ora vistas como uma instância democrática de comunicação, participação e controle social. Assim, seria a condição mediadora das Ouvidorias somente um mecanismo para reduzir e amortecer os conflitos entre a sociedade e o Estado, ou poderia apresentar-se como espaço de defesa e garantias de direitos de cidadania?

A construção de espaços públicos, enquanto canais de publicização de informações e mediação, com qualidade ou característica democrática, tem se demonstrado como um poderoso instrumento de ação política capaz de promover debates sobre os distintos interesses da sociedade, desde que tais espaços garantam condições de explicitar a heterogeneidade de projetos políticos que atravessam o binômio Estado-sociedade.

Do ponto de vista da participação e do controle social, o projeto democrático-participativo se alinha com a proposta de prestação de contas, controle social do público e garantia de direitos, "abrindo uma via para a participação cidadã cogestacionária com vistas à responsabilização dos servidores públicos (eleitos ou não)". Já o projeto liberal propõe a prestação de contas "na perspectiva de assegurar melhor comunicação e, portanto, uma maior eficiência na relação do Estado com os cidadãos clientes, contribuindo, assim, com a governabilidade" (DAGNINO et al., 2006, p. 50). Desse modo, tais ações podem se limitar à gerência e à execução de políticas públicas, mas podem, também, envolver a participação cidadã cogestacionária, assim como a participação com perspectivas de garantia de direitos e controle social do público através da prestação de contas do Estado à sociedade. Pode-se interrogar, novamente, sobre o papel das Ouvidorias na inter-relação Estado-sociedade: seriam elas compreendidas pelo viés mercadológico, como atendimento ao usuário-cliente, ou pelo viés da democracia, proporcionando ao cidadão um canal de defesa e exercício de sua cidadania? Entende-se, então, que o espaço público é o local privilegiado de mediação e 
interação da sociedade civil com o Estado, no qual questões pré-formuladas na sociedade civil são capazes de promover uma cultura política destinada à socialização do poder político do Estado. Nesse caso, a dimensão pública e estatal das Ouvidorias, enquanto "guardiãs dos direitos do povo", representaria uma dimensão do espaço público, na garantia de acesso dos indivíduos à participação e controle social.

Assim, o aprendizado da gestão pública passa a ser um percurso em meio às fortes tensões e contradições que compõem os espaços públicos e canais de mediação pública, seja por causa da heterogeneidade característica do Estado e da Sociedade Civil, seja pela assimetria de poder gerada pela cisão Estado/Sociedade e as diferenças presentes entre os representantes inter e intrainstitucionais e seus respectivos interesses. Como enfatiza NOGUEIRA (2004), "teremos assim que preparar (técnica, política e culturalmente) o Estado para impulsionar uma nova fase de desenvolvimento. Se vivemos em um contexto de relativo déficit institucional, no que se refere às instituições estatais e à presença efetiva do projeto do 'não Estado", continua o autor, "a melhor aposta repousa na recuperação democrática e social do Estado".

Tanto quanto de uma reforma que mantenha em lugar de destaque a viabilização da governança democrática; a ampliação da capacidade de governar, formular e implementar políticas públicas coerentes, e o aumento da eficiência, da capacidade republicana de gerir corretamente os tributos arrecadados do cidadão, precisamos também de uma reforma que recupere o Estado para a sociedade e que o coloque numa escala superior de valorização e de relevância. (NOGUEIRA, 2004, p.76)

A cultura política democrática ou clientelista dos pactos políticos entre Estado e sociedade, que se pretende (re)produzir nesse caminho, está delimitada e mediada por intervenções oriundas tanto de contextos governamentais quanto de contextos sociais, ambos fragmentados nas formas e níveis de mobilização, organização social e diversidade de projetos políticos. Torna-se fundamental reconhecer, nos tempos atuais, que é necessária uma nova cultura política, organizacional e relacional capaz de ressignificar as relações de interdependência do bloco Estado e Sociedade; revitalizar a noção de participação, cogestão, responsabilidades individuais e coletivas etc.; superar gradualmente os projetos unilaterais, seja via mercado, sociedade civil ou Estado, e constituir parâmetros para construção gradual da articulação de diferentes interesses em torno de um processo renovado de implementação de projetos destinados à transformação social. Essas ações poderiam valorizar a participação social e cidadã, sem incorrer no risco de despertar uma crise de Estado, ou crises institucionais, o que normalmente se teme quando se assiste ao avanço da corrupção em contextos burocráticos, permeados pelos mandos e desmandos partidários.

Nesse ponto, salienta-se o papel decisivo que cabe ao Estado em garantir um contrato social, que, por sua autoridade e/ou pelo consenso, seja capaz de assumir a mediação democrática, de maneira a reformular o setor público, numa nova predisposição ética para com os demais setores da sociedade (mercado, sociedade civil, sindicatos, movimentos sociais e populares etc.), assim como estabelecer novos parâmetros à participação da sociedade - passíveis de compor acordos políticos e sociais em torno dos problemas coletivos que denotam o bem comum -, garantindo as liberdades básicas, o controle público e a gestão democrática e efetiva das questões essencias do Estado. 
Assim, o principal desafio residiria em transformar questões específicas ou particulares em questões gerais e representações de interesses públicos e coletivos, ou seja, qualificar o poder público na capacidade de promover a subsunção dos interesses imediatos aos interesses futuros, equilibrando a dinâmica do interesse pessoal com a dinâmica do bem público. É aqui que as Ouvidorias se encontram na encruzilhada entre os interesses públicos e particulares, entre o direito de cidadania e o controle social, podendo servir para ampliação de espaços de participação, disseminação de informações, como também constituir importante instrumento de gestão e planejamento, apontando, por um lado, as insatisfações dos cidadãos no atendimento de suas expectativas e necessidades e, por outro, oferecendo visibilidade às ações do Estado ao público e potencializando o pleno exercício da democracia e garantia do Estado de direito.

\section{CONSIDERAÇÕES FINAIS}

As Ouvidorias brasileiras ampliam-se gradualmente e são fortalecidas pelos próprios cidadãos que depositam neste espaço suas mais diversas manifestações, solicitações e insatisfações a respeito do acesso aos serviços públicos e de sua qualidade. Idealmente, os cidadãos, ao elegerem este espaço de interlocução e mediação, voltado a aproximá-los das instituições e gestores públicos, confiam seus anseios e necessidades e aguardam um retorno, consagrando, desta forma, um acordo de confiabilidade e de reconhecimento da importância da participação social.

Com base no apresentado, que se propôs articular a cultura política e as questões referentes à institucionalização da participação social nos mecanismos de controle e acompanhamento das políticas públicas no processo de democratização do Estado e da sociedade brasileira, concomitantemente ao processo de emergência e expansão dos mecanismos de controle interno e social representado pelas Ouvidorias Públicas, propomos cinco questões para serem incorporadas à agenda de debates sobre as Ouvidorias Públicas. Em primeiro lugar, identificar a necessidade de se criar um referencial teórico-analítico em comum para o trabalho dos Ouvidores com relação ao atendimento às políticas públicas, no contexto de participação democrática e de um papel educativo junto ao cidadão, objetivando transformar a cultura da reclamação em cultura da participação. Em segundo, identificar os modelos de Ouvidorias que existem no país, criando uma tipologia que explique as diferentes formas de atuação, aprofundando os discursos ideológicos presentes nos debates atuais das Ouvidorias e aferindo as realidades e possibilidades existentes. Em terceiro, garantir o conhecimento social das Ouvidorias frente à opinião pública, publicizando objetivos, funções e seus resultados para a sociedade. Em quarto, considerar a dimensão intersetorial em que se insere o trabalho da Ouvidoria e garantir - às equipes de Ouvidores - conhecimentos especializados sobre políticas setoriais e sobre a Administração Pública, oferecendo-lhes, por meio de capacitação, ferramentas objetivas de procedimentos e parâmetros para sua prática, como indicadores, modelos de avaliação, planejamento, tecnologia de monitoramento, gestão das informações e riscos etc.; decorre daí a possibilidade de articulação intersetorial e espaços de realização de discussões e trabalhos conjuntos entre Ouvidores e Administração Pública, com o envolvimento e apoio das secretarias setoriais, no sentido de estabelecer conceitos, requisitos e condições estruturais para o 
funcionamento adequado das Ouvidorias. E, por último, discutir melhorias nos modelos atualmente aplicados, incluindo a realização de relatórios estratégicos para gestão, controle interno e promoção de efetivas melhorias nos serviços públicos oferecidos ao cidadão brasileiro.

\section{REFERÊNCIAS}

ANTUNES, C. K. S.; FREITAS, M. B.; JUNIOR, F. R. Ouvidoria: inter-relação entre o controle social e controle interno. Espaço Acadêmico Ouvidoria IPEA. Disponível em: <http://www.ipea.gov.br/ouvidoria/index.php?option=com content\&view=article\&id=201:ouvidoria-inter-relacao-entre-o-controle-social-e-controle-interno\&catid=14\&ltemid=18> Acesso em: 25 maio 2015

ARENDT, H. Condição Humana. Rio de Janeiro: Forense Universitária, 1995.

AVRITZER, L. Reforma Política e Participação no Brasil. In: AVRITZER, L.; ANASTASIA, F. (Org.). Reforma Política no Brasil. Belo Horizonte: UFMG, 2006. p. 35-45.

BRASIL. Constituição Federal: promulgada em 5 de outubro de 1988.

CARVALHO, J. M. Cidadania no Brasil: o longo caminho. 2. ed. Rio de Janeiro: Civilização Brasileira, 2004.

COSTA, F. L.. A Ouvidoria como instrumento para a efetividade da ação pública e promoção da cidadania. Revista Brasileira de Administração Pública. Rio de Janeiro, v. 32, n. 1, p. 167-170. Disponível em:

< www.ibape.fgv.br/academico/asp/dsp_professor.asp> Acesso em: 29 maio 2016.

COSTA, S. La Esfera Pública y las mediaciones entre cultura y política: el caso de Brasil. Metapolítica. v. 3, n. 9 , 1999. p. 95-107.

DAGNINO, E. Sociedade Civil, participação e cidadania: de que estamos falando? In: MATO, D. Políticas de ciudadanía y sociedad en tiempos de globalización. Caracas: FACES, Universidad Central de Venezuela, 2004. p. 95-110.

DAGNINO, E.; OLVERA, A. J.; PANFICHI, A. Para uma outra leitura sobre a disputa pela construção democrática na América Latina. In: DAGNINO, E.; OLVERA, A. J.; PANFICHI, A. (Org.). A disputa pela construção democrática na América Latina. São Paulo: Paz e Terra, 2006.

DRAIBE, S. As políticas sociais e o neoliberalismo - Reflexões suscitadas pelas experiências latino-americanas. Revista Usp, São Paulo, n. 17, p. 86-101, 1994.

Repensando a Política Social: dos Anos 80 ao início dos 90. In: PAULANI, L. M.; SOLA, L. (Org.) Lições da década de 80. São Paulo: Editora da Universidade de São Paulo, 1995. p. 201-224.

Ciclos de reformas de políticas públicas em ambiente de consolidação da democracia: a experiência brasileira recente de reforma dos programas sociais. Cadernos Núcleo de Estudos de Políticas Públicas - NEPP/UNICAMP, 2005. Disponível em: <http://www.nepp.unicamp.br/Cadernos/Caderno63.pdf> Acesso em: 13 jun. 2014.

FAORO, R. Os Donos do Poder - Formação do patronato político brasileiro. São Paulo: Editora Globo, 2001.

GECD - GRUPO DE ESTUDOS SOBRE A CONSTRUÇÃO DEMOCRÁTICA. Dossiê: Os movimentos sociais e a construção democrática. Esfera Pública e Democracia no Brasil. Ideias - Revista do Instituto de Filosofia e Ciências Humanas, Campinas: Unicamp, n. 5/6, p. 43-75, 1999.

GOMES, M. E. C. Regime jurídico das Ouvidorias Públicas: elementos para uma tipologia. In: VISMONA, Edson (Org.). A Ouvidoria brasileira. São Paulo: ABO/Imprensa Oficial do Estado de São Paulo, 2005. p. 55-78.

Ouvidorias Públicas: elementos para uma tipologia com fundamento no regime jurídico. In: Pinto E.; Lyra

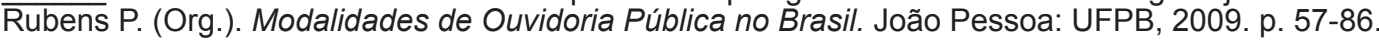

JOHN, Peter. Analysing public policy. Londres: Pinter, 1999.

LYRA, R. P. Ouvidorias Públicas e Privadas: Farinha do mesmo Saco? In: PINTO, E.; LYRA, R. P. (Org.) Modalidades de Ouvidoria Pública no Brasil. João Pessoa: UFPB, 2009. p. 89-105. 
HAM, C.; HILL, M. The policy process in the modern capitalist state. Londres, 1993.

LAVALLE, A. G. Sem pena nem glória: o debate sobre a sociedade civil nos anos 1990. Novos Estudos. CEBRAP, n. 67, p. 91-109, 2003.

MEDEIROS, M. A trajetória do Welfare States no Brasil: papel redistributivo das políticas sociais dos anos 1930 aos anos 1990. Brasília, 2001. Disponível em: < http://www.ipea.gov.br.> Acesso em: 21 jun. 2016.

MARSHALL, T.H. Cidadania, Classe Social e Status. Rio de Janeiro: Zahar, 1967.

NÚCLEO DE POLÍTICAS PÚBLICAS - NEPP. Avaliação de Políticas e Programas Sociais. Caderno de Pesquisa. Campinas: UNICAMP, 1989.

O sistema de proteção social no Brasil. Campinas: UNICAMP, 1991.

NOGUEIRA, M. A. Sociedade Civil, entre o Político-Estatal e o Universo Gerencial. Revista Brasileira de Ciências Sociais, v. 18, n. 52, p. 187-202, jun. 2003.

2004

Um Estado para a Sociedade Civil - Temas éticos e políticos da gestão democrática. São Paulo: Ed. Cortez,

PINTO, E.; LYRA, R. P. (Org.). Modalidades de Ouvidoria Pública no Brasil. João Pessoa: UFPB, 2009. 335 p.

RUS PEREZ, J.R.; BARREIRO, A. E. A.; PASSONE, E. F. K. (Org.) Construindo a Ouvidoria no Brasil: Avanços e Perspectivas. Campinas: Ed. UNICAMP, 2011. p. 59-76.

SANTOS, B. Para uma reinvenção solidária e participativa do Estado. In: BRESSER PEREIRA, L. C.; WILHEIM J.; SOLA L. (Org.) Sociedade e Estado em transformação. São Paulo: Editora Unesp, 2001.

SANTOS, W.G. A trágica condição da política social. In: ABRANCHES, S. et al. (Org.) Política Social e combate à pobreza. Rio de Janeiro: Jorge Jahar, 1989. p. 33-63.

Cidadania e Justiça: a política social na ordem brasileira. Rio de Janeiro: Campos, 1979.

VISMONA, E.L.; BARREIRO A.E.A. (Org.) Ouvidoria Brasileira: o cidadão e as instituições. São Paulo, 2015. 